\title{
Determination of An Optimum Cut-off Point for \% fPSA/tPSA to Improve Detection of Prostate Cancer
}

\author{
Vineeth* G Nair and M. H. Shariff
}

Department of Pathology, Yenepoya Medical College, Karnataka, India

\begin{abstract}
Background: Total serum prostate specific antigen (tPSA) and free prostate specific antigen (fPSA) are known to be useful in the detection of prostate carcinoma (PCa). It has been reported that \% fPSA/tPSA is more accurate when it comes to distinguishing PCa from non-malignant conditions such as BPH. The recommended cut-off value of \%fPSA/tPSA in western countries is $20-25 \%$. Through this study, we aim to determine an optimum cut-off value for $\% \mathrm{fPSA} / \mathrm{tPSA}$ in an Indian population.
\end{abstract}

Methods: This study was performed at our institution between September 2015 and August 2016. The study population included 181 patients who had prostate enlargement and who then underwent PSA based prostate cancer screening with tPSA and \%fPSA/tPSA and whose diagnosis was later confirmed by histopathology. An ROC curve analysis was performed to determine sensitivity, specificity and other performance characteristics. The optimum cut-off value of \%fPSA/tPSA was determined from ROC curve using Youden's index.

Result: Malignant histology was seen in 17 (9.4\%) cases. ROC curve analysis of \%fPSA/tPSA revealed an AUC value of 0.777 . The cutoff value of \%fPSA/tPSA having the optimum balance between sensitivity and specificity was found to be $12.07 \%$ (Sensitivity: $70.6 \%$, Specificity: $84.8 \%$, Positive predictive value: 0.324 , Negative predictive value: 0.965 , Positive likelihood ratio: 4.631 and Negative likelihood ratio: 0.347$)$.

Conclusion: The cut-off value of \%fPSA/tPSA obtained from our study (12.07\%), which was conducted on a South Indian population, is different from the cut-off values seen in western countries and in many studies conducted in western populations.

\section{Keywords: Prostate Specific Antigen, Prostatic neoplasms, ROC Curve, Prostatic Hyperplasia}

\section{Introduction}

Serum PSA levels are commonly used for early detection of prostate cancer (PCa) ${ }^{[1]}$ Many conditions - including benign ones - can, however, cause an increase in the serum PSA levels. ${ }^{[2]} \mathrm{A}$ few studies also indicate that not all cases of PCa are associated with a high PSA level. ${ }^{[3]}$

PSA exists in the plasma as a complex with serine protease inhibitors. These include $\alpha 1$-antichymotrypsin, $\alpha 1$-protease inhibitor, and $\alpha 2$-macroglobulin. ${ }^{[4]}$ However, approximately $10-30 \%$ of the total PSA (tPSA) is not bound to serum proteins. ${ }^{[5]}$ This is termed free PSA (fPSA). [5] Studies have shown that a lower ratio/percentage of free PSA to total PSA (\% $\mathrm{fPSA} / \mathrm{tPSA}$ ) is seen in PCa as compared to benign conditions. ${ }^{[5]}$ It was then found that $\% \mathrm{fPSA} / \mathrm{tPSA}$ could be useful in detecting $\mathrm{PCa}$ in patients whose serum PSA values lie within the gray zone i.e. 4-10 $\mathrm{ng} / \mathrm{mL} .{ }^{[6]}$ It has also been reported that $\% \mathrm{fPSA} / \mathrm{tPSA}$ is a more accurate when it comes to distinguishing $\mathrm{PCa}$ from non-malignant conditions such as $\mathrm{BPH}{ }^{[7]}$

The recommended cut-off value of $\% \mathrm{PPSA} / \mathrm{tPSA}$ in western countries is $20-25 \% \cdot{ }^{[8[9]}$ Through this study, we aim to determine an optimum cut-off value for $\%$ PPSA/tPSA in an Indian population.

\section{Materials and Methods:}

This study was performed at our institution between September 2015 and August 2016. The study population included 181 patients who had prostate enlargement and who then underwent PSA based prostate cancer screening with tPSA and \%fPSA/tPSA and whose diagnosis was later confirmed by histopathology. Serum tPSA levels were measured using an immunometric assay (Vitros 5600, Ortho-clinical diagnostics, Buckinghamshire, UK) with an analytical sensitivity of $0.036 \mathrm{ng} / \mathrm{ML}$. Serum fPSA was analysed by immunometric assay (Vitros 5600, Ortho-clinical diagnostics, Buckinghamshire, UK) with an analytical sensitivity of $0.007 \mathrm{ng} / \mathrm{mL}$. \%fPSA/tPSA values were automatically calculated by the VITROS 5600 .

Data analysis was performed in SPSS version 23. Continuous data was expressed as mean or as median. A confidence interval of $95 \%$ was employed if the distribution was not normal. Sensitivity, specificity, positive predictive value and negative predictive value was calculated via 
receiver operator curve analysis. Values of area under the curve were also calculated used the same. A p-value of less than the significance level alpha $=0.05$ was considered significant. Optimum cut-off value was calculated from the ROC using Youden's index.

\section{Result}

The study population comprised of a total of 181 male patients with a mean age of $65.02 \pm 8.62$ years. The youngest was 45 years and the oldest 90 years of age. Prostate malignancy was detected in 17 cases $(9.39 \%)$. Of these, no patient was below the age of 50 years and the mean age of patients diagnosed with prostate malignancy is $69.88 \pm 8.61$ years.

The mean tPSA level for patients with prostate malignancy and benign histology were $93.82 \mathrm{ng} / \mathrm{mL}$ (95\% CI: $30.46-$ $157.19 \mathrm{ng} / \mathrm{mL})$ and $5.26 \mathrm{ng} / \mathrm{mL}(95 \% \mathrm{CI}: 4.10-6.42 \mathrm{ng} /$ $\mathrm{mL}$ ) respectively $(\mathrm{p}$ value $=0.001)$. The mean fPSA level for patients with prostate malignancy and benign histology were $18.31 \mathrm{ng} / \mathrm{mL}$ (95\% CI: $0.67-35.94 \mathrm{ng} / \mathrm{mL})$ and 0.84 $\mathrm{ng} / \mathrm{mL}(95 \% \mathrm{CI}: 0.68-0.99 \mathrm{ng} / \mathrm{mL}$ ) respectively (p value $<0.001)$. The mean $\%$ fPSA/tPSA level for patients with prostate malignancy and benign histology were 13.41\% (95\% CI: 8.11\%-18.71\%) and 21.93\% (95\% CI: $20.19-$ $23.66)$ respectively $(\mathrm{p}$ value $=0.006)$.

$\%$ fPSA/tPSA had an area under the curve (AUC) value of 0.77 (95\% CI: 0.643-0.911) in detecting prostate malignancy indicating that, in our study, it did indeed serve as a good distinguishing marker. Fig.1 shows the ROC curve of $\% \mathrm{fPSA} / \mathrm{tPSA}$ ratio.

According to Youden's index applied to the ROC curve analysis, the \%fPSA/tPSA value with the optimum balance between sensitivity and specificity was $12.07 \%$ (Sensitivity: 70.6\%, Specificity: $84.8 \%$, Positive predictive value: 0.324 , Negative predictive value: 0.965 , Positive likelihood ratio: 4.631 and Negative likelihood ratio: 0.347$)$.

Table 1: Characteristics of Benign Histology Group and Malignant Histology Group.

\begin{tabular}{|l|c|c|c|}
\hline & BENIGN HISTOLOGY (N=164) & MALIGNANT HISTOLOGY (N=17) & p VALUE (<0.05 is significant) \\
\hline Age $(\mathrm{yrs})$ & 64.51 & 69.88 & 0.012 \\
\hline Mean tPSA $(\mathrm{ng} / \mathrm{mL})$ & 5.26 & 93.82 & 0.001 \\
\hline Mean fPSA $(\mathrm{ng} / \mathrm{mL})$ & 0.91 & 18.31 & $<0.001$ \\
\hline Mean \%fPSA/tPSA (\%) & 21.93 & 13.41 & 0.006 \\
\hline
\end{tabular}

Table 2: Sensitivity, Specificity, PPV(Positive predictive value), NPV(Negative Predictive Value), PLR(Positive Likelihood Ratio) and NLR(Negative Likelihood Ratio) of \%fPSA/tPSA at different cut-off values and at cut-off value determined from the ROC curve by Youden's index (12.07\%).

\begin{tabular}{|l|c|c|c|c|c|c|c|}
\hline & $\mathbf{5 \%}$ & $\mathbf{1 0} \%$ & $\mathbf{1 5 \%}$ & $\mathbf{2 0} \%$ & $\mathbf{2 5 \%}$ & $\mathbf{3 0 \%}$ & $\mathbf{1 2 . 0 7 \%}$ \\
\hline SENSITIVITY & 11.8 & 52.9 & $\mathbf{7 0 . 6}$ & 82.4 & 88.2 & 94.1 & $\mathbf{7 0 . 6}$ \\
\hline SPECIFICITY & 97.6 & 92.1 & 70.1 & 46.3 & 31.1 & 18.9 & 84.8 \\
\hline PPV & 0.33 & 0.45 & 0.19 & 0.14 & 0.12 & 0.11 & 0.32 \\
\hline NPV & 0.91 & 0.95 & 0.96 & 0.96 & 0.96 & 0.97 & 0.97 \\
\hline PLR & 4.82 & 7.89 & 2.36 & 1.53 & 1.28 & 1.16 & 4.63 \\
\hline NLR & 0.90 & 0.50 & 0.40 & 0.38 & 0.38 & 0.31 & 0.35 \\
\hline
\end{tabular}

Table 3: Comparison between cut-off value of \%fPSA/tPSA as determined by our study with other studies conducted in the past.

\begin{tabular}{|l|c|}
\hline STUDY & \%FPSA/TPSA CUTOFF VALUE \\
\hline Our Study & $12 \%$ \\
\hline Prcic et al (2016) & $16 \%$ \\
\hline Yilmaz et al (2015) & $10 \%$ \\
\hline Thakur et al (2014) & $12 \%$ \\
\hline Pormand et al (2012) & $13 \%$ \\
\hline Suzuki et al (2006) & $10 \%$ \\
\hline Chun et al (2006) & $25-31 \%$ \\
\hline Safarinejad et al (2006) & $18 \%$ \\
\hline Partin et al (2001) & $15 \%$ \\
\hline Dalva et al (1999) & $15 \%$ \\
\hline Catalona et al (1998) & $25 \%$ \\
\hline
\end{tabular}




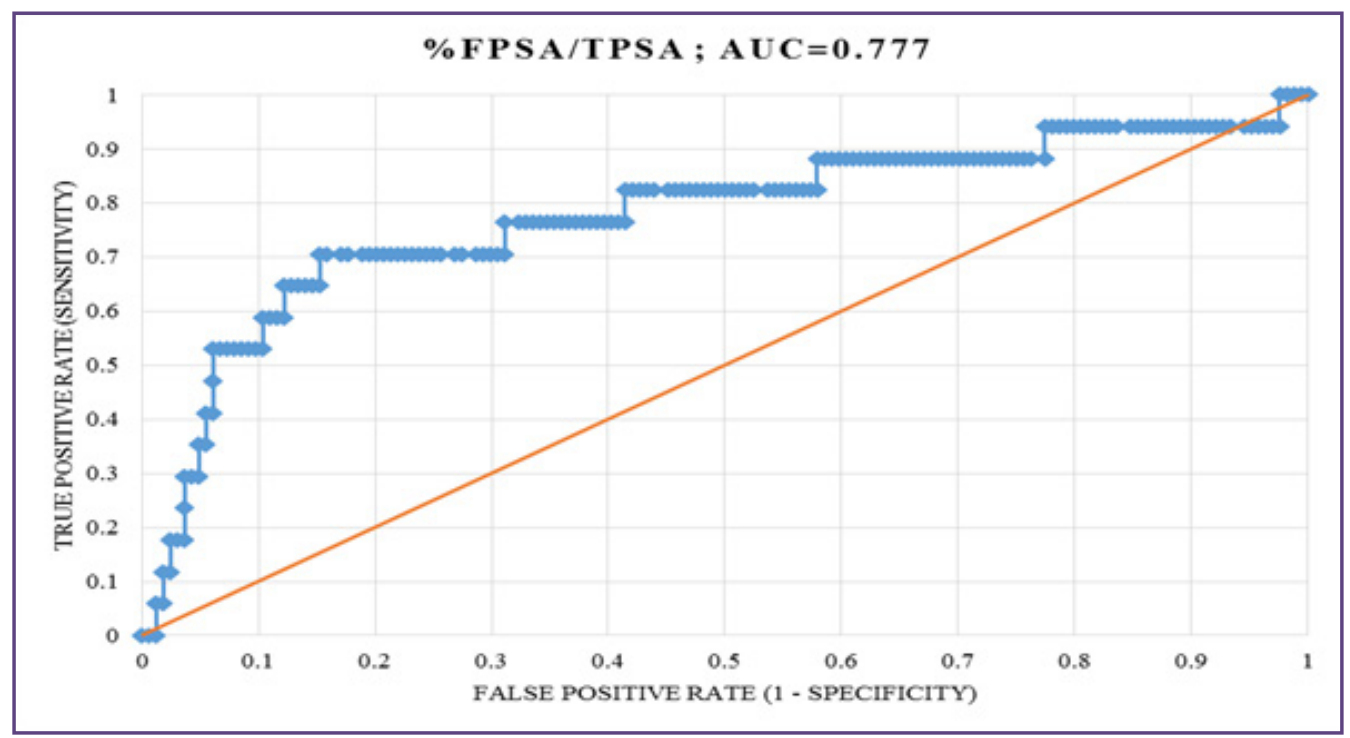

Fig. 1: ROC curve of \%fPSA/tPSA.

\section{Discussion}

PSA was first detected in serum in 1980 and since then it has become essential to the management of prostate cancer $(\mathrm{PCa}) .{ }^{[10]} \mathrm{PSA}$ in the human body is required for liquefaction of semen and it is secreted into the seminal plasma. ${ }^{[1]}$ The release of significant quantities of PSA into the main bloodstream is rare in a healthy individual and as such happens only when there is destruction of the basement membrane of the prostate epithelium. ${ }^{[12]}$ This occurs not only in $\mathrm{PCa}$ but also in benign conditions. [2] Hence, increased serum PSA levels are not prostate specific. ${ }^{[2]}$ However, a strong correlation between serum PSA and prostate cancer has been proven. ${ }^{[13][14]}$ The advent of immunoassays made it possible to measure fPSA in various forms. This made it possible to calculate \%fPSA. $\%$ fPSA was first utilised by Stenman et al and Christensson et al. ${ }^{[4][15]}$ It has been demonstrated to be more efficient in distinguishing or differentiating patients with benign prostate histology from those with malignant histology than serum tPSA levels alone. ${ }^{[16]}$

It has been proven that patients with increased serum tPSA concentrations have a higher probability for PCa. It has also been proven that these same patients tend to have a lower \% $\%$ PSA than patients with benign prostatic disease. ${ }^{[8]}$ In our study as well, we found that there was a statistically significant lowering of \%fPSA values in cases of malignant disease as compared to benign prostate disease.

It has also been studied and demonstrated that \%fPSA or f/tPSA helps improve the discrimination between PCa and benign conditions especially in cases where serum tPSA is between $4 \mathrm{ng} / \mathrm{mL}$ and $10 \mathrm{ng} / \mathrm{mL}$. This helps reduce unnecessary prostate biopsies by helping identify the cases where the need for a biopsy is clear and present. ${ }^{[17][18][19]}$

An optimum cut-off value for \%fPSA, as with any screening test, is essential as it can lead to better and more accurate detection of PCa. Many studies have been conducted amongst various populations to determine cut-off values for better distinguishing PCa from benign lesions.

Our study shows that a cut-off value of $12 \%$ gives the optimum balance between sensitivity and specificity (Sensitivity: $70.6 \%$, Specificity: $84.8 \%$ ). This $12 \%$ cut-off value gives an excellent negative predictive value of 0.965 $(96.5 \%)$ which means that a patient with a \%fPSA value of more than $12 \%$ has a $96.5 \%$ probability of not having $\mathrm{PCa}$.

A study conducted by Safarinejad et al concluded that a $\mathrm{f} / \mathrm{tPSA}$ cut-off value of $0.18(\% \mathrm{fPSA}=18 \%)$ is optimum having a sensitivity of $94.5 \% \cdot{ }^{[20]}$ Partin et al suggested that a cut-off value of $15 \%$ would detect all advanced tumours while avoiding $80 \%$ of unnecessary biopsies, especially in men whose serum tPSA value lie in the "gray" zone (4 to $10 \mathrm{ng} / \mathrm{mL}$ ). ${ }^{[21]}$ Catalona et al suggested that a cut-off value of $24 \%$ would help detect $90 \%$ of PCa and avoid appox $18 \%$ of benign disease in patients with a serum tPSA value of 2.6 to $4 \mathrm{ng} / \mathrm{mL}^{[7]} \mathrm{In}$ a later update by the same authors, a variety of cut-off values were examined and they concluded that a cut-off value of $25 \%$ was optimal. ${ }^{\text {[22] }}$ Chun et al suggested using median age-specific cut-off values for \%fPSA which ranged from $25-31 \%$, and below which the risk of prostate cancer was high. ${ }^{[23]}$ Suzuki et al. reported a $26 \%$ decrease in the number of unnecessary biopsies and a sensitivity of $90 \%$ when a cut-off value of $10 \%$ was applied. ${ }^{[24]}$ Prcic et al found the best combination 
of sensitivity and specificity (sensitivity $=72.3 \%$ and specificity $=50.4 \%$ ) was at a cut-off of $16 \% \cdot{ }^{[25]}$ Yilmaz et al suggested a cut-off of $10 \%$ whereas Pourmand et al arrived at $13 \%{ }^{[26][27]}$ The study conducted by Dalva et al came to a cut-off value of $15 \%{ }^{\left[{ }^{[28]} \mathrm{A}\right.}$ study conducted on an Indian population (sample size - 101 patients) by Thakur et al determined a cut-off value of $12 \% .{ }^{[29]}$

\section{Conclusion}

In conclusion, the current study shows that the optimum cut-off value for \%fPSA/tPSA which gives the best balance between sensitivity and specificity is $12.07 \%$. This value is seen to be different from the cut-off values determined by most other studies, but this may be explained by the differing populations that were the subject of these studies, most of which were conducted in Western countries. The study by Thakur et al which was done on an Indian population yielded a cut-off value almost identical to ours. As it stands, further study with larger sample sizes is warranted for confirmation of our findings in the Indian context.

\section{Abbreviations and Symbols:}

$\mathrm{PCa}$ - Prostate Cancer

tPSA - Total serum prostate specific antigen

fPSA - Free serum prostate specific antigen

$\%$ fPSA/tPSA - Serum free-to-total prostate specific antigen ratio/percentage

ROC - Receiver Operating Characteristic

AUC - Area Under the Curve

PPV - Positive predictive value

NPV - Negative Predictive Value

PLR - Positive Likelihood Ratio

NLR - Negative Likelihood Ratio

\section{Reference}

1. Polascik TJ, Oesterling JE, Partin AW. Prostate specific antigen: a decade of discovery e what we have learned and where we are going. J Urol 1999;162:293e306.

2. Dalva I, Akan H, Yildiz O, Telli C, Bingol N. The clinical value of the ratio of free prostate specific antigen to total prostate specific antigen. Int Urol Nephrol. 1999;31:675-80.

3. Carter HB. Prostate cancers in men with low PSA levels-must we find them? N Engl J Med. 2004;350:2292

4. Stenman UH, Leinonen J, Alfthan H, Rannikko S, Tuhkanen $\mathrm{K}$, Alfthan O. A complex between prostate specific antigen and alpha 1-antichymotrypsin is the major form of prostatespecific antigen in serum of patients with prostatic cancer: assay of the complex improves clinical sensitivity for cancer. Cancer Res. 1991;51:222-6.

5. Amirrasouli H, Kazerouni F, Sanadizade M, Sanadizade J, Kamalian N, Jalali M et al. Accurate cut-off point for free to total prostate-specific antigen ratio used to improve differentiation of prostate cancer from benign prostate hyperplasia in Iranian population. Urol J. 2010;7(2):99-104.

6. Luderer AA, Chen YT, Soriano TF, Kram WJ, Carlson G, Cuny $\mathrm{C}$, et al. Measurement of the proportion of free to total prostate specific antigen improves diagnostic performance of prostate specific antigen in the diagnostic gray zone of total prostate specific antigen. Urology 1995;46:187e94.

7. Catalona WJ, Smith DS, Wolfert RL, Wang TJ, Rittenhouse HG, Ratliff TL, et al. Evaluation of percentage of free serum prostate-specific antigen to improve specificity of prostate cancer screening. J Am Med Assoc 1995; 274:1214e20.

8. Catalona WJ, Partin Aw, Slawin KM, et al. Use of the percentage of free prostate-specific antigen to enhance differentiation of prostate cancer from benign prostatic disease: a prospective multicenter clinical trial. Jama. 1998;279:1542-7.

9. Ito K, Yamamoto T, Ohi M, Kurokawa K, Suzuki K, Yamanaka H. Free/total PSA ratio is a powerful predictor of future prostate cancer morbidity in men with initial PSA levels of 4.1 to $10.0 \mathrm{ng} / \mathrm{mL}$. Urology. 2003;61:760-4.

10. Polascik TJ, Oesterling JE, Partin AW. Prostate specific antigen: a decade of discovery - what we have learned and where we are going. J. Urol. 1999;162: 293-306.

11. Lilja H, Oldbring J, Rannevik G, Laurell CB. Seminal vesicle-secreted proteins and their reactions during gelation and liquefaction of human semen, J. Clin. Invest. 1987;80:281-285.

12. Stenman UH, Prostate-specific antigen, clinical use and staging: an overview. Br. J. Urol. 1997:79(Suppl.1):53-60.

13. Aus G, Damber JE, Khatami A, Lilja H, Stranne J, Hugosson J. Individualized screening interval for prostate cancer based on prostate-specific antigen level: results of a prospective, randomized, population-based study. Arch. Intern. Med. 2005; 165:1857-1861.

14. Thompson IM, Pauler DK, Goodman PJ, Tangen CM, Lucia MS, Parnes HL et al. Prevalence of prostate cancer among men with a prostate-specific antigen level $\mathrm{b}$ or $=4.0 \mathrm{ng}$ per milliliter, N. Engl. J. Med. 2004;350:2239-2246.

15. Christensson A, Bjork T, Nilsson O, et al. Serum prostate specific antigen complexed to alpha 1-antichymotrypsin as an indicator of prostate cancer. J Urol. 1993;150:100-5.

16. Catalona wJ, Smith DS, Ratliff TL, Basler Jw. Detection of organ-confined prostate cancer is increased through prostatespecific antigen-based screening. Jama. 1993;270:948-54.

17. Catalona WJ, Partin AW, Slawin KM, Brawer MK, Flanigan $\mathrm{RC}$, Patel A, et al. Use of percentage of free prostate specific antigen to enhance differentiation of prostate cancer from benign prostatic disease: a prospective multicenter trial. J Am Med Assoc 1998;279:1542e7.

18. van Cangh PJ, De Nayer P, De Vischer L, Sauvage P, Tombal $\mathrm{B}$, Lorge $\mathrm{F}$, et al. Free to total prostate-specific antigen (PSA) ratio improves the discrimination between prostate 
cancer and benign prostatic hyperplasia (BPH) in the diagnostic gray zone of 1.8 to $10 \mathrm{ng} / \mathrm{mL}$ total PSA. Urology 1996;48:67e70.

19. Catalona WJ, Partin AW, Slawin KM, Naughton CK, Brawer MK, Flanigan RC, et al. Percentage of free PSA in black versus white men for detection and staging of prostate cancer: a prospective multicenter clinical trial. Urology 2000;55:372e6.

20. Safarinejad MR. Population-based screening for prostate cancer by measuring free and total serum prostate-specific antigen in Iran. Ann Oncol. 2006 Jul;17(7):1166-71.

21. Partin AW, Mangold LA, Lamm DM, Walsh PC, Epstein JI, Pearson JD. Contemporary update of prostate cancer staging nomograms (Partin Tables) for the new millenium. Urology 2001;58:843e8.

22. Catalona WJ, Partin AW, Slawin KM, Brawer MK, Flanigan RC, Patel A, et al. Use of percentage of free prostate specific antigen to enhance differentiation of prostate cancer from benign prostatic disease: a prospective multicenter trial. J Am Med Assoc 1998;279:1542e7.

23. Chun FK, Perrotte P, Briganti A, Benayoun S, Lebeau T, Ramirez A, et al. Prostate specific-antigen distribution in asymptomatic Canadian men with no clinical evidence of prostate cancer. BJUI 2006;98:50e3.
24. Suzuki H, Komiya A, Kamiya N, Takashi I, Koji K, Junichiro $\mathrm{M}$, et al. Development of a nomogram to predict probability of positive initial prostate biopsy among Japanese patients. Urology 2006;67:131e5.

25. Prcic A, Begic E, Hiros M. Actual Contribution of Free to Total PSA Ratio in Prostate Diseases Differentiation. Med Arch. 2016;70(4):288-292.

26. Yilmaz H, Ciftci S, Yavuz U, Ustuner M, Saribacak A, Dillioglugil O. Percentage of free prostate-specific antigen (PSA) is a useful method in deciding to perform prostate biopsy with higher core numbers in patients with low PSA cut-off values. Kaohsiung J Med Sci. 2015;31(6):315-9

27. Pourmand G, Ramezani R, Sabahgoulian B, Nadali F, Mehrsai AR, Nikoobakht,MR et al. Preventing Unnecessary Invasive Cancer-Diagnostic Tests: Changing the Cut-off Points.Iran J Public Health. 2012; 41(2): 47-52.

28. Dalva I, Akan H, Yildiz O, Telli C, Bingol N. The clinical value of the ratio of free prostate specific antigen to total prostate specific antigen. Int Urol Nephrol. 1999;31:675-8.

29. Thakur V, Talwar M, Singh P. Low free to total PSA ratio is not a good discriminator of chronic prostatitis and prostate cancer: An Indian experience. Indian Journal of Cancer 2014;51(3):335.

*Corresponding author:

Dr. Vineeth G Nair, Room 412, “A” Block, Gardyenia PG Hostel, Yenepoya University Campus, Deralakatte, Mangalore, Karnataka - 575018, India

Phone: +91 9972917978

Email: dr.vgn86@gmail.com

Date of Submission : 03.01.2017

Date of Acceptance : 20.04.2017

Financial or other Competing Interests: None. 